\title{
MECHANO-SORPTIVE BEHAVIOUR OF EUCALYPTUS PELLITA DURING INTERMITTENT AND CONTINUOUS DRYING
}

\author{
Yuniarti K \\ Forest Products Research and Development Center, Jl Gunung Batu 5 Bogor 16610 West Java, Indonesia \\ karnitayuniarti2015@gmail.com
}

Submitted March 2018; accepted July 2018

\begin{abstract}
Intermittent drying can reduce collapse shrinkage rate and decrease internal checks within certain timbers. This study was aimed at investigating and comparing mechano-sorptive behaviour, which explained the stress/strain formation of Eucalyptus pellita during intermittent and continuous drying regimes. The study applied $50^{\circ} \mathrm{C}$ for the heating phase of one continuous and two intermittent regimes. One intermittent regime had its temperature raised to $55^{\circ} \mathrm{C}$ when the samples reached below fibre saturation point. The study showed that the intermittent regimes reduced shrinkage strains in E. pellita by $0.004-0.031$. The instantaneous strain in the surface of $E$. pellita boards exposed to intermittent regime was $0.001-0.007$ smaller than those in the continuously dried boards. Nevertheless, the selected regimes caused viscoelastic and mechano-sorptive strains as large as or much larger than those in the continuous regime. Compressive stress was a dominant stress causing the shrinkage strain formation in E. pellita boards exposed to both drying regimes. Other strains were affected by the combination of compressive and tensile stress developed in the middle and/or surface of the boards. Statistical tests confirmed the significant effect of the drying technique applied, not the provenance factor, on mechano-sorptive behaviour of E. pellita.
\end{abstract}

Keywords: Intermittent regime, shrinkage strain, instantaneous strain, viscoelastic strain, mechano-sorptive strain

\section{INTRODUCTION}

Mechano-sorptive behaviour of wood is often used to understand stress formation during wood drying. Mechano-sorptive behaviour generally refers to the effects resulting from interaction between developed stress in wood and moisture change (Zhan \& Avramidis 2011a, b). Under this theory, the strain which developes during drying of wood comprises four components, namely, instantaneous or elastic strain, shrinkage strain, viscoelasticcreep strain and mechano-sorptive strain (Wu \& Milota 1994, Chen \& Gu 2006, Zhan \& Avramidis 2011a).

Currently, many studies of the mechanosorptive behaviour are still limited to the effects of various continuous drying conditions (Wu \& Milota 1994, Zhan \& Avramidis 2011b). Drying conditions affect the development and degree of moisture gradient and stress in the wood as well as the amount of shrinkage generated within the wood (Lazarescu et al. 2009, Zongying et al. 2016). Mechano-sorptive behaviour of wood exposed to intermittent drying has not attracted much attention. The first study of this issue was carried out by Langrish (2013) who used computational modelling. His simulation indicated the superiority of intermittent drying over continuous drying in lowering the magnitude of stress.

Intermittent drying is different from conventional drying process. The inclusion of non-heating phases between the heating phases in intermittent drying could be a way to add more humidity into the kiln. It redistributes the internal moisture, leading to more even moisture gradient and stress relaxation. Intermittent drying is able to reduce collapse, shrinkage rate in the tangential and radial directions and the amount of internal checks within certain timbers (Chadwick \& Langrish 1996, Yuniarti 2015).

Intermittent drying is often considered as potential option for drying refractory species such as Eucalyptus pellita. This species 
is widely used for plantation programmes throughout Asia, including Indonesia. It is also considered as potential raw material for construction purposes and veneer and/ or plywood production (Hii et al. 2017). Nevertheless, E. pellita often develops defects during drying process, limiting its further uses (Latorraca et al. 2015). Information on the application of intermittent drying and its effect on the mechano-sorptive behaviour of E. pellita is not yet available. The type of species affects either drying performance or mechano-sorptive behaviour of wood under certain drying condition (Wu \& Milota 1994). Provenance or genetic factor also affects the mechano-sorptive behaviour of wood. Provenance factor influences not only the tree growth but also several wood properties such as density, modulus of elasticity and modulus of rupture (Sahri et al. 1998, Montes \& Weber 2009). Variation in wood properties, in particular density, due to differences in provenance could lead to different stress development within the same species during drying process. Due to important gaps in the knowledge regarding intermittent drying and its effect on mechano-sorptive behaviour of $E$. pellita, this research was aimed at:

(1) investigating mechano-sorptive behaviour of E. pellita under various intermittent regimes and comparing it with samples from the continuous regime, and

(2) identifying the effect of provenance on the mechano-sorptive behaviour of E. pellita during drying.

\section{MATERIALS AND METHODS}

Ten-year-old E. pellita trees from two provenances, namely, Serisa Village, Papua New Guinea (hereafter PNG) and Bupul Muting, Indonesia (Indonesia) were used for this study. The trees were collected from the research forest area in Wonogiri, Central Java which was managed by the Center for Forest Biotechnology and Tree Improvement (CFBTI), Yogyakarta. Six trees from each provenance were collected from two planting blocks in the same area. Each tree was cut approximately at 100-mm height from above the ground. All trees were sawn in to several 4000-mm long logs from bottom to top. Each small log was coded to mark its original position in the standing tree, which was A for logs from the bottom part, $\mathrm{B}$ for the middle part and $\mathrm{C}$ for the top part. A total of 36 logs from the two provenances were produced and transported to the Center for Forest Products Research and Development in Bogor. These logs were stored outside the sawing laboratory without protection.

\section{Sample preparation}

The logs of the two provenances were selected randomly and further cut to produce flat sawn boards with dimensions $4000 \mathrm{~mm}$ (L) $\times$ $100 \mathrm{~mm}(\mathrm{~W}) \times 25 \mathrm{~mm}(\mathrm{~T})$. Each flat sawn board was further cut into drying samples measuring $500 \mathrm{~mm}(\mathrm{~L}) \times 100 \mathrm{~mm}(\mathrm{~W}) \times 25 \mathrm{~mm}(\mathrm{~T})$ each and free shrinkage samples measuring $20 \mathrm{~mm}(\mathrm{~L})$ $\times 100 \mathrm{~mm}(\mathrm{~W}) \times 25 \mathrm{~mm}(\mathrm{~T})$ each. The cutting pattern is illustrated in Figure 1.

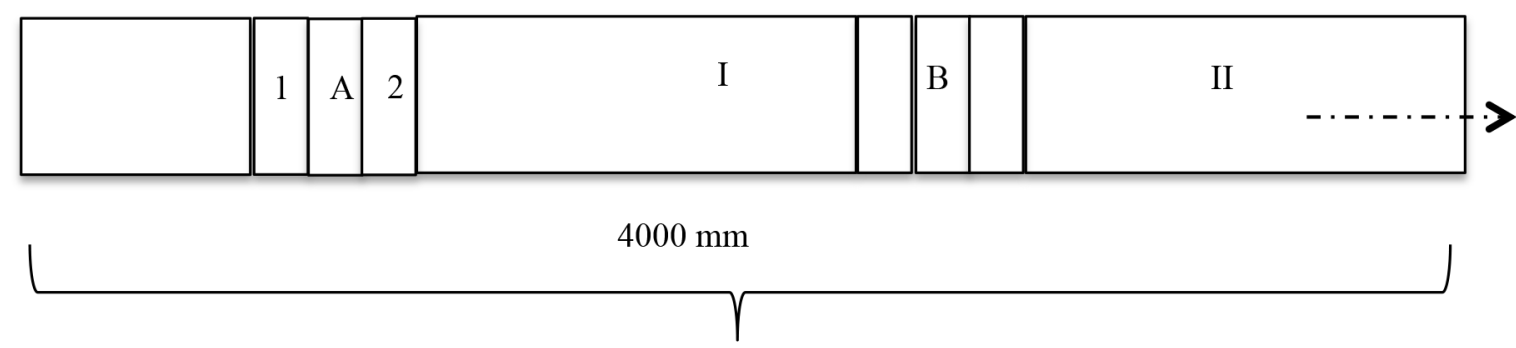

$\mathrm{A}, \mathrm{B}=20$-mm long free shrinkage samples

1,2 = initial moisture content biscuits ( $20 \mathrm{~mm}$ long)

I, II = 500-mm long drying samples

- - $\cdot \cdot \cdot \cdot->\quad$ Cutting stops when no more samples can be obtained from each 4000-mm long board

Figure 1 Cutting pattern of drying and free shrinkage samples for intermittent and continuous drying trials (from the original 4000-mm long board) 
Prior to drying trials, all drying samples were end-sealed with sealant and aluminum foil. The samples were marked according to Figure 2 to ease the collection of 20-mm long strain biscuits after heating and non-heating phases. Each strain biscuit was further marked and divided into several slices along their thickness. The initial width of each slice was then measured.

\section{Drying trials}

Samples were exposed to two different intermittent regimes and one continuous regime with no relative humidity applied during the drying process. The treatments were:

(1) continuous regime which used a temperature of $50{ }^{\circ} \mathrm{C}$ through the drying process,

(2) intermittent regime 1 which applied 8 hours of heating phase at $50{ }^{\circ} \mathrm{C}$ and 16 hours of nonheating phase at ambient condition daily, and

(3) intermittent regime 2 which had the same condition as intermittent regime 1 until fibre saturation point. Whilst keeping the 16-hour non-heating phase at ambient condition, daily heating phase was carried out for 8 hours at $55{ }^{\circ} \mathrm{C}$.

The change between heating and nonheating phases for the two intermittent regimes was carried out daily. The heating period was employed during working hours from 8 a.m. to 4 p.m. and the non-heating period was applied from 4 p.m. to 8 a.m. All drying trials were run until the samples reached the target moisture content (10-15\%). Moisture content was measured manually twice daily using weightscale method.

Each drying treatment was run twice in laboratory ovens as drying kilns were not available. In this study, all drying regimes only employed temperature as the drying factor. This condition represents the drying process adopted by, in particular, small- to medium-scale wooden industries in several developing countries due to knowledge and financial support limitation.

The main parameters of the mechano-sorptive behaviour observed were instantaneous strain, shrinkage strain, viscoelastic strain/creep and mechano-sorptive strain. The parameters were observed at two observation levels: (1) at fibre saturation point (moisture content range of $25-30 \%)$ and (2) at final moisture content $(10-15 \%)$. Moisture contents within the samples at the observation levels were also recorded.

All samples from each run were allocated randomly into different observation levels. When the samples for a particular observation level reached the targeted moisture content, the samples were taken from the oven after each heating or non-heating phase. Approximately 20-mm long strain biscuits were sawn at a distance of $50 \mathrm{~mm}$ from one end. The ends of the remaining samples were sealed and returned to the oven. Each strain biscuit was immediately weighed and wrapped with plastic and aluminum foil to prevent moisture evaporation. While being wrapped, the biscuits were marked to divide them into several sections along the thickness and parallel to one face, from top to the bottom of the board (Figure 3). The width of each section was

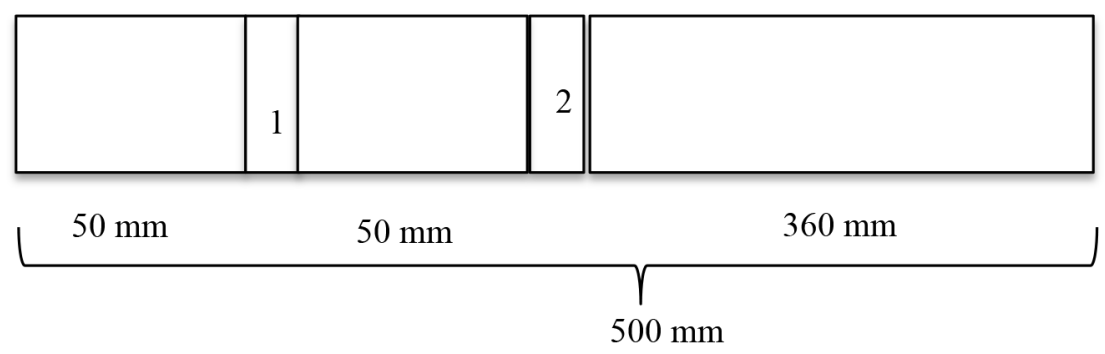

Figure 2 The collection pattern of the 20-mm long strain biscuits after heating phase (1) and non-heating phase (2)

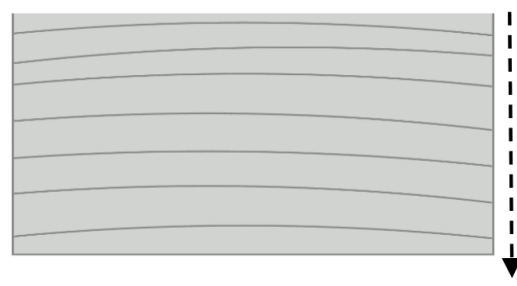

Slicing direction from top to bottom of the boards (from slice 1 to 4 )

Figure 3 Slicing direction of sample biscuits from top to bottom of the boards 
measured. After marking, the wrap was removed. Each section was cut, and its length was measured and weighed. All slices from each biscuit were immediately wrapped together with plastic film. Each set of slices was clamped together to prevent warping and stored at ambient temperature for 24 hours after which the length and weight of each slice were measured again. The slices were then oven dried at $103{ }^{\circ} \mathrm{C}$ for 24 hours. The next day, the weight and width of each slice were recorded again. The procedure above is similar to that used by Wu and Milota (1994) but with the modification of the number of slices being cut, i.e 8 vs 4 slices in this study, and the slicing direction. The biscuits were sliced along the thickness and the slice numbering was in the same direction as the growth rings. Therefore, slices numbers 1 and 4 represented the top and bottom surfaces of each board respectively, and slices numbers 2 and 3 represented the middle parts of each board.

Free shrinkage samples obtained as in Figure 1 were exposed to the same intermittent and continuous regimes and also allocated into two observation levels randomly. Their initial weights and dimensions prior to the drying trial were measured. When the samples allocated in a particular observation level reached the targeted moisture content, the samples were taken out of the oven and reweighed immediately. The free shrinkage samples were then marked and divided into different four parts along the thickness, from top to bottom of the boards, similar to the treatment for the biscuits in the drying trials (Figure 3). The width of each part was measured by digital callipers and recorded.

\section{Data collection and analysis}

Data collected and used for the mechano-sorptive behaviour analysis are as follows:

L0 = initial width of each slice of each strain biscuit prior to being dried ( $\mathrm{mm}$ )

$\mathrm{L} 1=$ pre-cut width of each slice of each strain biscuit at corresponding observation level $(\mathrm{mm})$

L2 = post-cut width of each slice of each strain biscuit at corresponding observation level $(\mathrm{mm})$

L3 = recovery width of each slice of strain biscuit at corresponding observation level $(\mathrm{mm})$

$\mathrm{L} 4=$ the width of free shrinkage samples at corresponding observation level $(\mathrm{mm})$
These values were used to determine the instantaneous strain, viscoelastic strain/creep, mechano-sorptive strain and shrinkage strain for each slice obtained from each biscuit. The determination of each strain followed equations 1 to 4 below. Negative value implies the presence of tension, while positive value indicates the slice is under compression (Fuller 2000, SepulvedaVillarroel et al. 2016). Moisture distribution of the slices from each strain sample was also collected and used as supporting data to show its relationship with strain development.

$$
\begin{aligned}
& \text { Shrinkage strain }=(\mathrm{L} 0-\mathrm{L} 1) / \mathrm{L} 0 \\
& \text { Instantaneous strain }=(\mathrm{L} 1-\mathrm{L} 2) / \mathrm{L} 0 \\
& \text { Viscoelastic strain }=(\mathrm{L} 2-\mathrm{L} 3) / \mathrm{L} 0 \\
& \text { Mechano-sorptive strain }=(\mathrm{L} 3-\mathrm{L} 4) / \mathrm{L} 0
\end{aligned}
$$

Analysis of variance (ANOVA) with main factors and subfactors nested in several main factors was further carried out to investigate and compare the effects of different drying regimes and provenance factors on the wood mechano-sorptive behaviour. The main factors considered for the analysis were the drying regimes, provenance factors and moisture content levels of the samples. The two subfactors, observation phase and slice parts, were nested in the main factors. The observation phase (after heating and non-heating phases) was nested in moisture content level, and slice part was nested in provenance factor.

\section{RESULTS AND DISCUSSION}

\section{Shrinkage strain}

Shrinkage strain occurs under stress. It starts to develop when moisture content of the timber reaches fibre saturation point (Chen \& Gu 2006). Figures $4-5$ show that strain increases towards the middle part from either the top or bottom surface of the boards. The pattern was the same across the two provenances. Strain values in the boards from intermittent drying were 0.004-0.031 smaller than those observed in continuously dried boards (Figures 4 and $5)$. Positive values indicated that the boards exposed to all treatment regimes experienced compression strain at both fibre saturation point and final moisture levels. The finding indicated that as the top and bottom surfaces of 


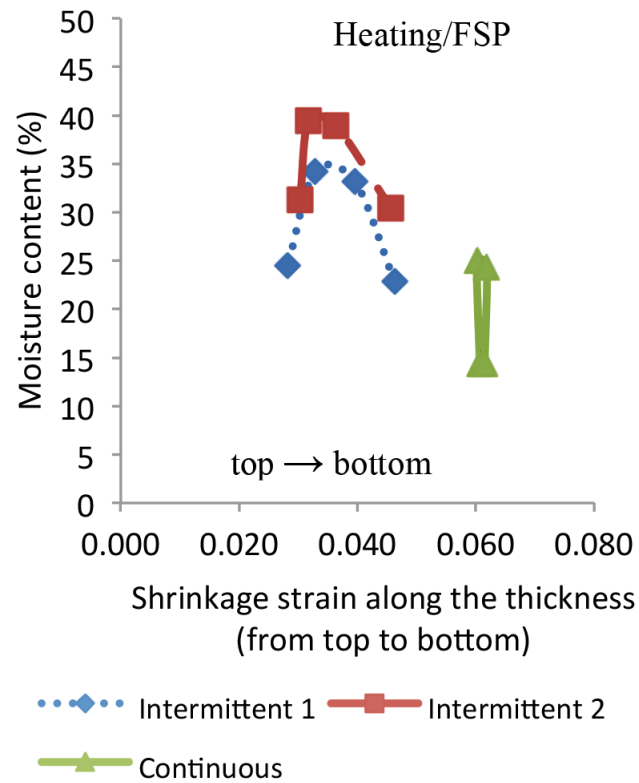

(a)

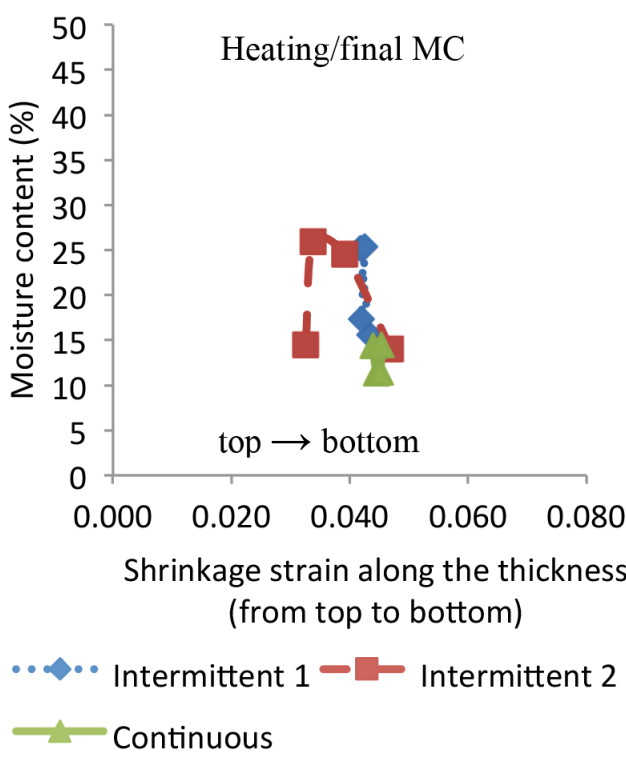

(c)

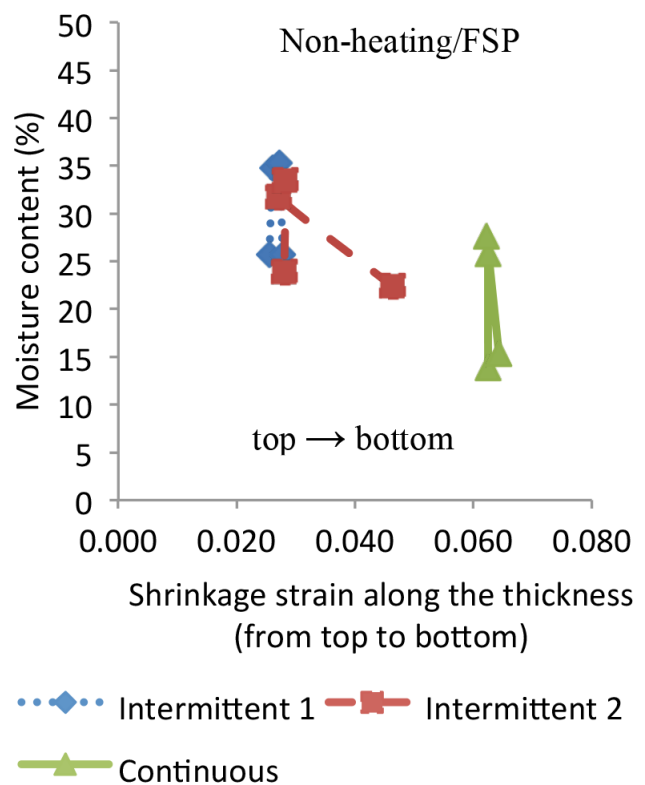

(b)

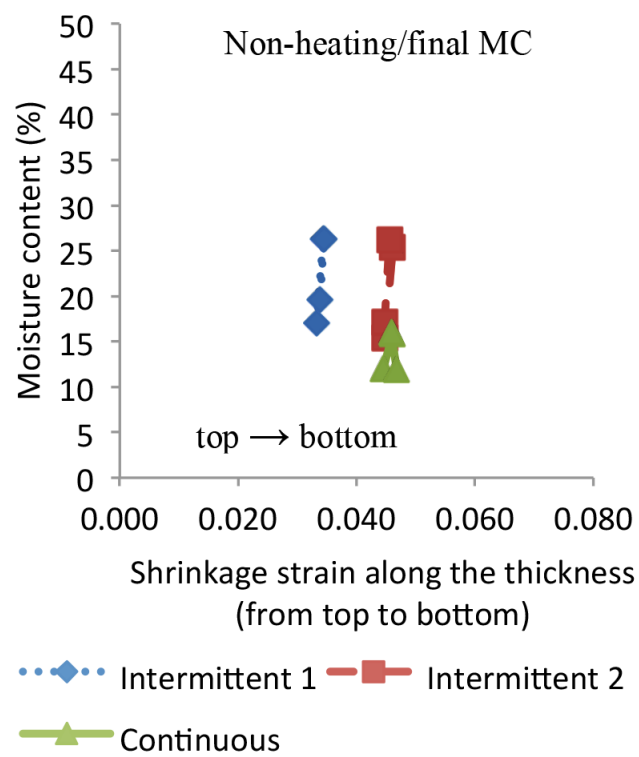

(d)

Figure 4 Shrinkage strain along the thickness of the boards from Serisa Village, Papua New Guinea provenance exposed to different drying conditions; (a)-(b) fibre saturation point level (FSP), (c)-(d) final moisture content (MC) level (10-15\%)

the boards got drier than the middle part of the boards, the wood portion from the same parts also shrank more. The differences in shrinkage rate between wood parts could cause surface check/crack. Thus, it is suggested that the inclusion of humidity during the non-heating phase in intermittent drying might decrease the development of surface check/crack as a more favourable moisture gradient is restored.
Moisture content profiles of all investigated boards developed a bell-shaped pattern from the top to the bottom surface of the boards (Figures 4 and 5). Moisture content of continuously dried boards were less than that of intermittently dried boards, indicating the continuous drying caused faster drying than the intermittent drying. This finding complements the study by Yuniarti (2015). 


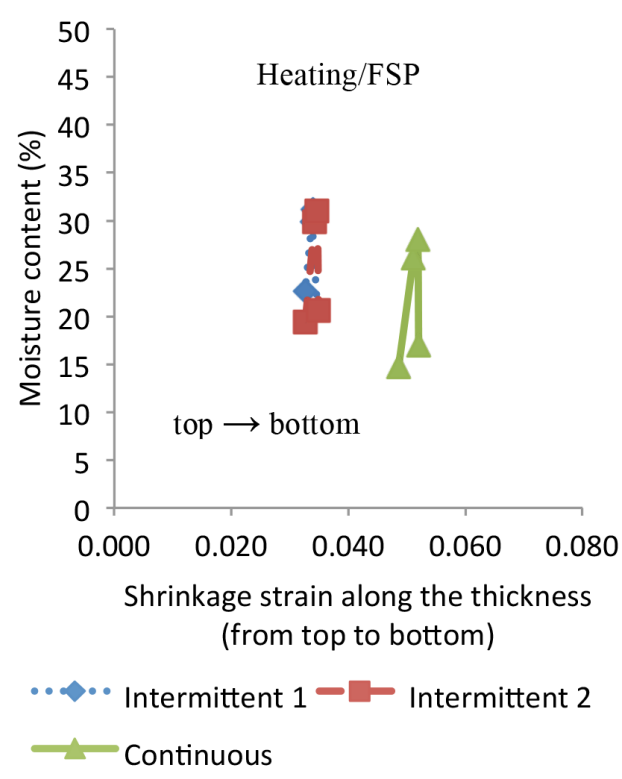

(a)

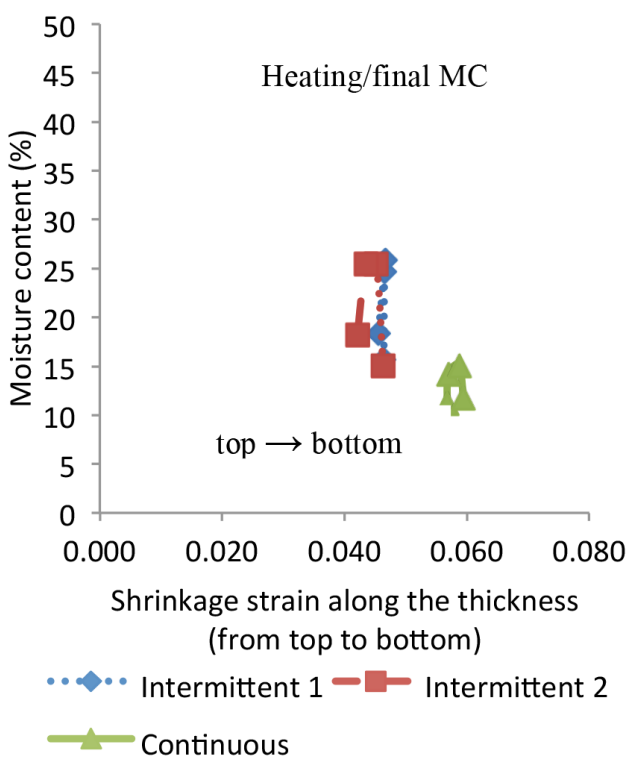

(c)

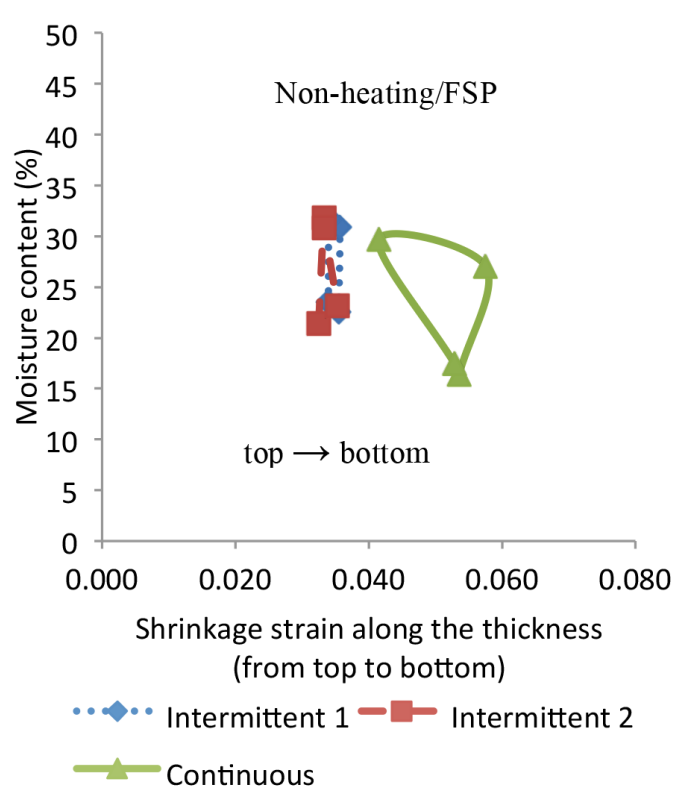

(b)

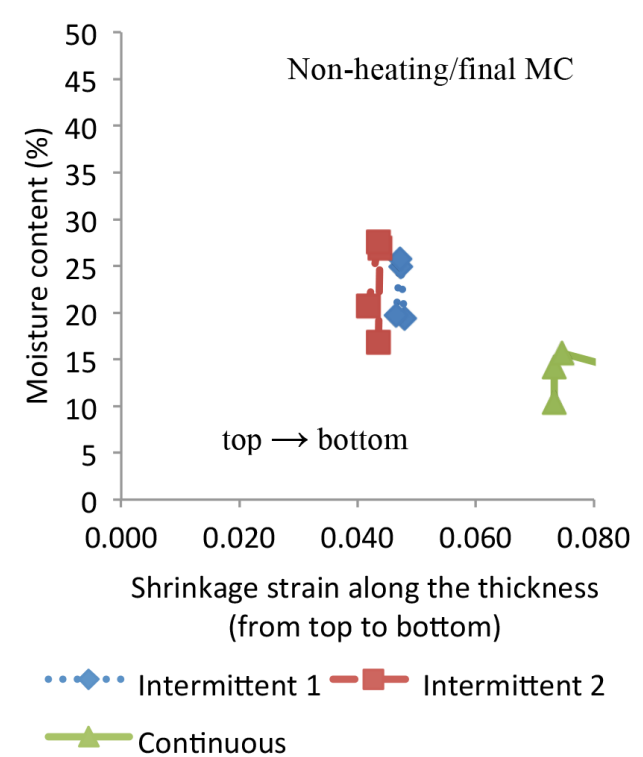

(d)

Figure 5 Shrinkage strain along the thickness of the boards from Bupul Muting, Indonesia provenance exposed to different drying conditions; (a)-(b) fibre saturation point (FSP) level, (c)-(d) final moisture content (MC) level (10-15\%)

Significant effects of drying technique and moisture content levels on shrinkage strain values were observed (Table 1). Additional Tukey's test confirmed significant differences in shrinkage strain between continuously and intermittently dried boards, but not between different intermittent regimes (Table 2).

\section{Instantaneous strain}

Instantaneous strain develops immediately following stress development in the wood $(\mathrm{Wu}$
\& Milota 1994). The strain is recoverable if the load or stress imposed on a sample is released before it exceeds its proportional limit (Haque 2002). Maximum instantaneous strain achieved in a wood being dried determines the optimum drying rate of the wood (Langrish \& Walker 2006).

Compressive stress dominated the instantaneous strain formation in the continuously dried boards from both provenances (Figures 6 and 7). The strain values increased towards the bottom surface of the boards. This indicated 
Table 1 Summary of analysis of variance for identifying factors affecting the strains investigated

\begin{tabular}{lcccc}
\hline Source of variation & \multicolumn{4}{c}{ Mehano-sorptive behaviour } \\
\cline { 2 - 5 } & Shrinkage & Instantaneous & Viscoelastic & Mechano-sorptive \\
\hline Batch & NS & NS & S & S \\
Drying regime & S & S & S & S \\
Provenance & NS & NS & NS \\
Moisture content (MC) & S & NS & NS & S \\
Observation (nested in MC) & NS & NS & S & NS \\
Slice (nested in provenance) & NS & S & & S \\
Interaction & & & NS & S \\
Drying*provenance*MC & NS & NS & NS & S \\
Drying*provenance & NS & NS & NS & NS \\
Drying*MC & NS & NS & NS & NS \\
Provenance*MC & NS & & & NS \\
\hline
\end{tabular}

$\mathrm{S}=$ significant, NS=non-significant

vulnerability of the wood section close to the pith in developing compressive stress. The strain in the middle part of the continuously dried boards was sometimes higher or lower than those in the intermittently dried boards. The strain in the top part of the continuously dried boards from both provenances was 0.001-0.007 greater than those observed in the intermittently dried boards at fibre saturation point and final moisture content. Boards underwent non-stop heating condition in the continuous regime, but not in the intermittent regime and this findings were expected. Therefore, intermittent drying may decrease the tendency of E. pellita boards to break beyond its proportional limit.

Instantaneous strain was significantly affected by the drying techniques and the slice factor which represented the top or middle parts of the boards (Table 1). Further Tukey 's test confirmed that the significant differences in instantaneous strain was only observed between continuously and intermittently dried boards (Table 2). Temperature significantly affects the instantaneous strain in a material (Haque 2002). The largest instantaneous strain was in the bottom part of the boards from Indonesia provenance. The result indicated that drying E. pellita boards from Indonesia provenance must be executed more carefully than those from PNG provenance.

\section{Viscoelastic strain}

Viscoelastic strain represents the delayed deformation caused by strain development under constant moisture (Chen \& Gu 2006). This deformation will usually occur following a period of stress relaxation, leaving only mechano-sorptive deformation within the samples (Zhan \& Avramidis 2011b). Viscoelastic strain in the surface and middle parts of E. pellita boards from both drying regimes was a combined result of tensile stress (negative values) and compressive stress (positive values) (Figures 8 and 9). This finding indicated that E. pellita will deform under the selected intermittent regimes. All figures showed the viscoelastic strain values along the board thickness were not much different, indicating that the deformation degree will possibly be uniform.

Viscoelastic strain in the middle parts of E. pellita boards from Indonesia provenance and exposed to intermittent regime 1 was 0.001-0.002 smaller than or similar to that developed in the continuously dried boards. The majority of boards from the intermittent regime 2 developed larger viscoelastic strain along the board thickness than those from intermittent regime 1 or continuous drying. Intermittent regime 1 decreased deformation in E. pellita boards. 
Table 2 Summary of Tukey's tests for identifying significant differences within the factors or their interactions which affect the investigated strains

\begin{tabular}{|c|c|c|c|c|}
\hline \multirow[t]{2}{*}{ Source of variation } & \multicolumn{4}{|c|}{ Mehano-sorptive behaviour } \\
\hline & Shrinkage strain & Instantaneous strain & $\begin{array}{l}\text { Viscoelasti } \\
\text { strain }\end{array}$ & $\begin{array}{c}\text { Mechano-sorptive } \\
\text { strain }\end{array}$ \\
\hline
\end{tabular}

Drying regime

1
2
3

A

A

B

Moisture content

Final moisture content (FMC)

A

Final moisture content (FSP)

Slice (nested in provenance)
Slice 1 PNG
Slice 1 (IND)
Slice 2 (PNG)
Slice 2 (IND)
Slice 3 (PNG)
Slice 3 (IND)
Slice 4 (PNG)
Slice 4 (IND)

Drying*provenance*moisture content

Drying $1 * \mathrm{PNG}$ FSP

Drying 1*PNG*FMC

Drying $1 *$ IND*FSP

Drying $1 *$ IND*FMC

Drying $2 * \mathrm{PNG}^{*} \mathrm{FSP}$

Drying $2 * \mathrm{PNG}^{*} \mathrm{FMC}$

Drying $2 *$ IND*FSP

Drying $2 *$ IND*FMC

Drying $3 * \mathrm{PNG}^{*} \mathrm{FSP}$

Drying $3 * \mathrm{PNG}^{*} \mathrm{FMC}$

Drying $3 *$ IND*FSP

Drying $3 *$ IND*FMC

Drying*provenance

Drying $1 *$ PNG

Drying $1 *$ IND

Drying 2*PNG

Drying $2 *$ IND

Drying $3 * \mathrm{PNG}$

Drying $3 *$ IND

Drying*moisture content

Drying $1 * \mathrm{FSP}$

Drying 1 *FMC

Drying $2 * \mathrm{FSP}$

Drying 2*FMC

Drying $3 * \mathrm{FSP}$

Drying $3 *$ FMC

B

$\begin{array}{lll}\text { A } & \text { A } & \text { A } \\ \text { A } & \text { A } & \text { B } \\ \text { B } & \text { B } & \text { A }\end{array}$

A

B

$\begin{array}{cc}\mathrm{ABC} & \mathrm{B} \\ \mathrm{AB} & \mathrm{B} \\ \mathrm{ABCD} & \mathrm{A} \\ \mathrm{CD} & \mathrm{A} \\ \mathrm{BCD} & \mathrm{A} \\ \mathrm{D} & \mathrm{A} \\ \mathrm{ABC} & \mathrm{B} \\ \mathrm{A} & \mathrm{B}\end{array}$

ABC

BC

$\mathrm{ABC}$

$\mathrm{ABC}$

$\mathrm{ABC}$

$\mathrm{A}$

$\mathrm{AB}$

$\mathrm{ABC}$

C

BC

BC

A

BC

$\mathrm{ABC}$

A

$\mathrm{AB}$

C

$\mathrm{ABC}$

$\mathrm{ABC}$

BC

$\mathrm{AB}$

A

C

AB

Provenance PNG refers to Serisa-Village, Papua New Guinea, Provenance IND refers to Bupul-Muting, Indonesia; drying regime 1 refers to intermittent 1, regime 2 refers to intermittent 2; and regime 3 refers to continuous; means that do not share the same letter are significantly different 


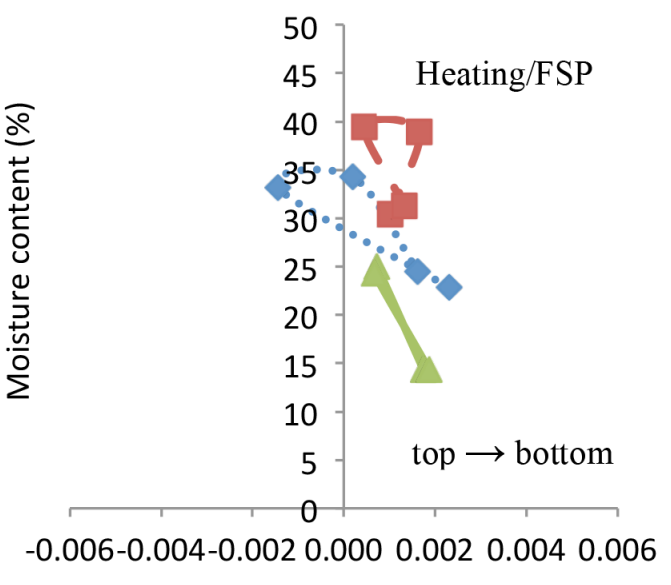

Strain along the thickness (from top to bottom)

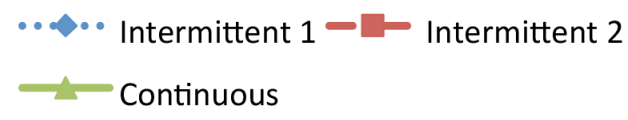

(a)

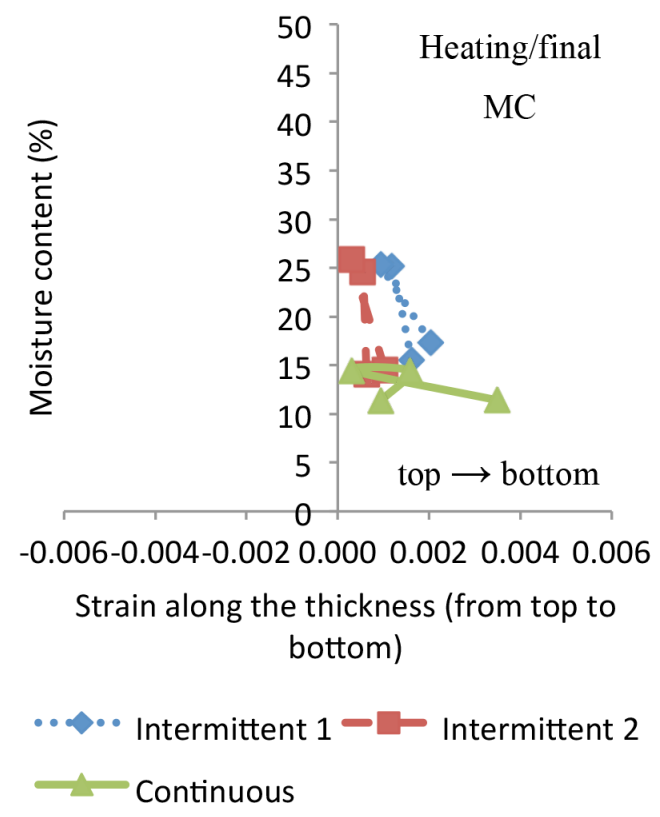

(c)

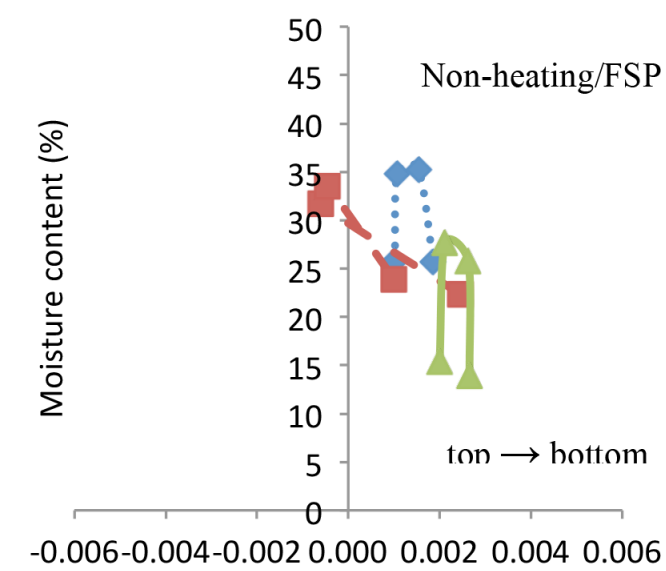

Strain along the thickness (from top to bottom)

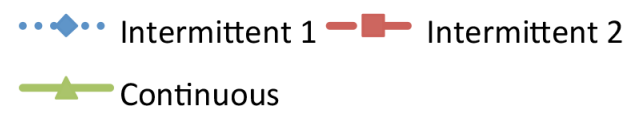

(b)

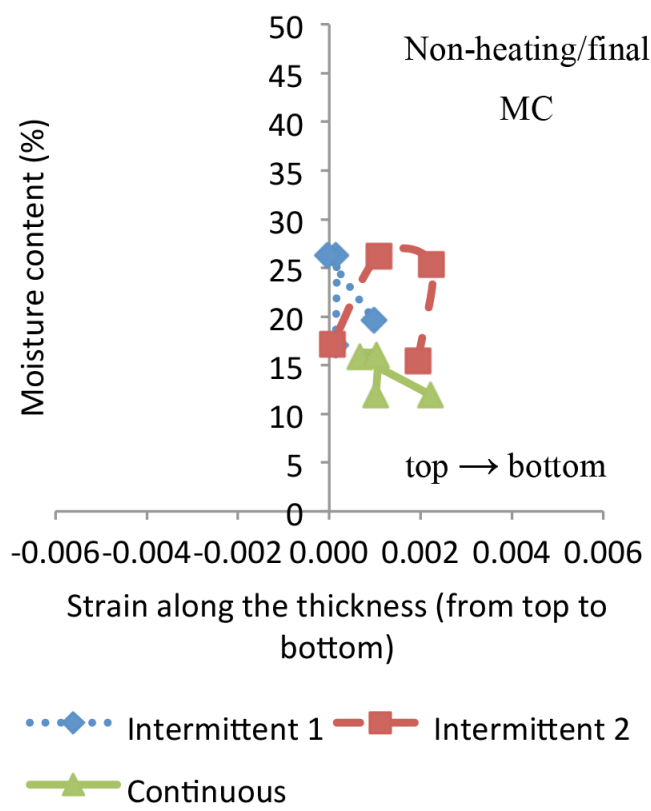

(d)

Figure 6 Instantaneous strain along the thickness of the boards from Serisa Village, Papua New Guinea provenance exposed to different drying conditions; (a)-(b) fibre saturation point (FSP) level, (c)-(d) final moisture content (MC) level (10-15\%)

ANOVA confirmed that drying technique and subfactor slice significantly affected the viscoelastic strain (Table 1). Tukey's test further confirmed significant differences in viscoelastic strain between continuous and all intermittent regimes (Table 2).

\section{Mechano-sorptive strain}

Mechanosoprtive strain represents an increasing, additional deformation as a reaction to the change in moisture content, temperature, and internal stress (Zhan \& Avramidis 2011b). 


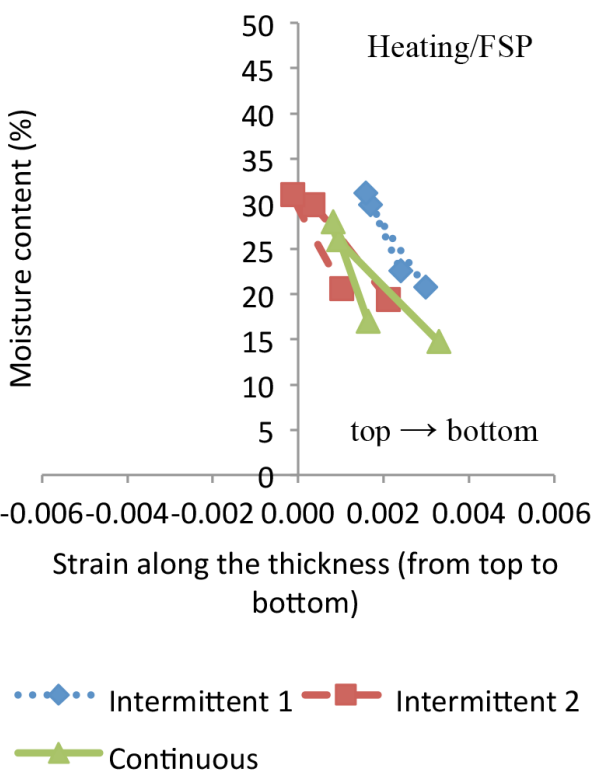

(a)

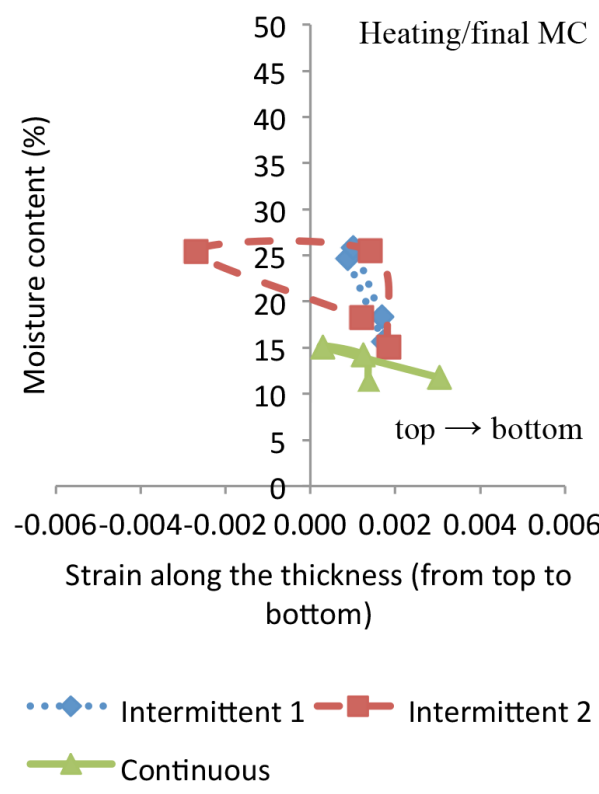

(c)

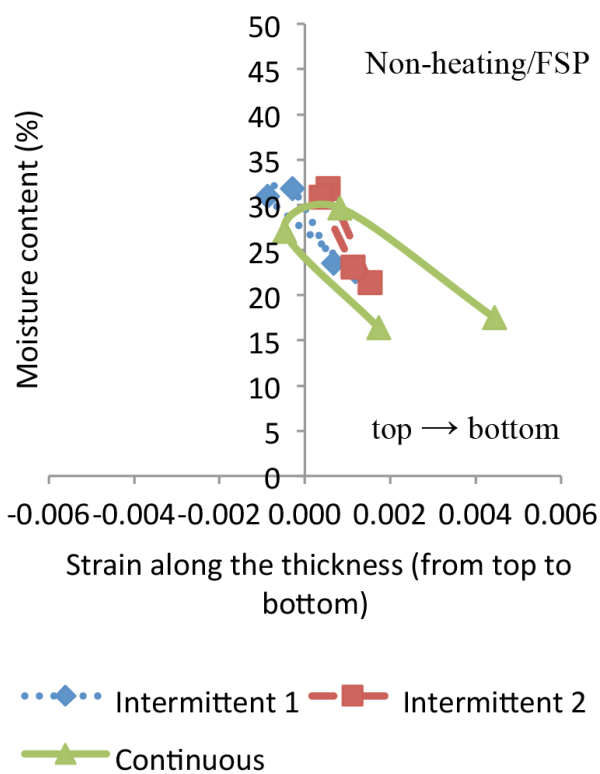

(b)

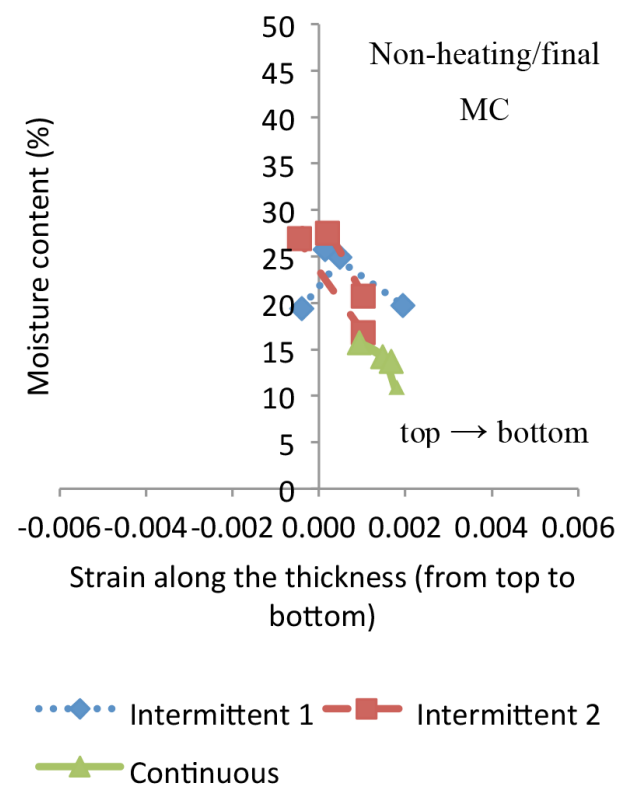

(d)

Figure 7 Instantaneous strain along the thickness of the boards from Bupul Muting, Indonesia provenance exposed to different drying conditions; (a)-(b) fibre saturation point (FSP) level, (c)-(d) final moisture content (MC) level (10-15\%)

The mechano-sorptive strain developed in E. pellita boards is a combined result between tensile and compressive stresses. The mechanosorptive strain in E. pellita boards from PNG provenance exposed to intermittent regime 1 or continuous drying was mainly caused by tensile stress at all moisture levels (Figure 10). The mechano-sorptive strain in the intermittently dried boards from Indonesia provenance was dominantly driven by compressive stress during the non-heating phase and tensile stress or both stresses during the heating phase (Figures 11). Compressive stress dominantly caused mechano-sorptive strain in E. pellita boards exposed to intermittent regime 2 (Figures 10 and 11). 


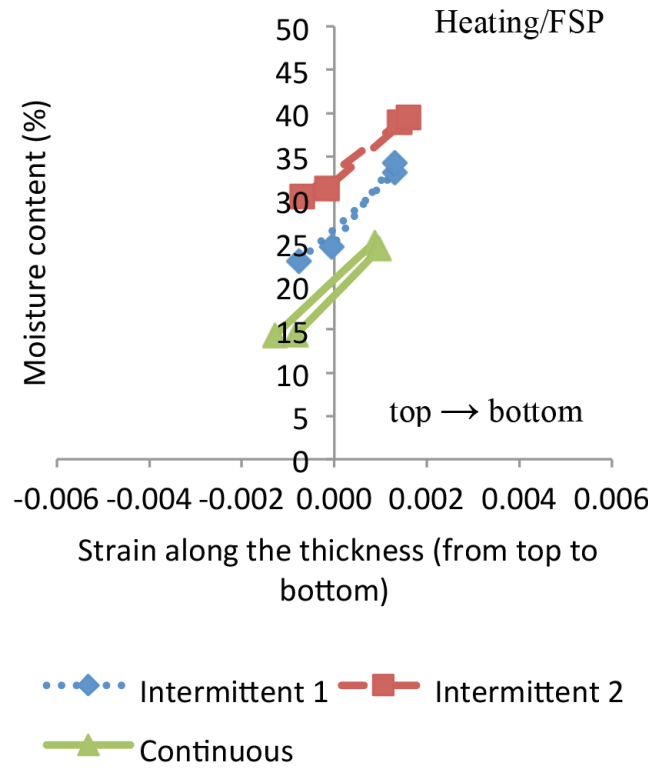

(a)

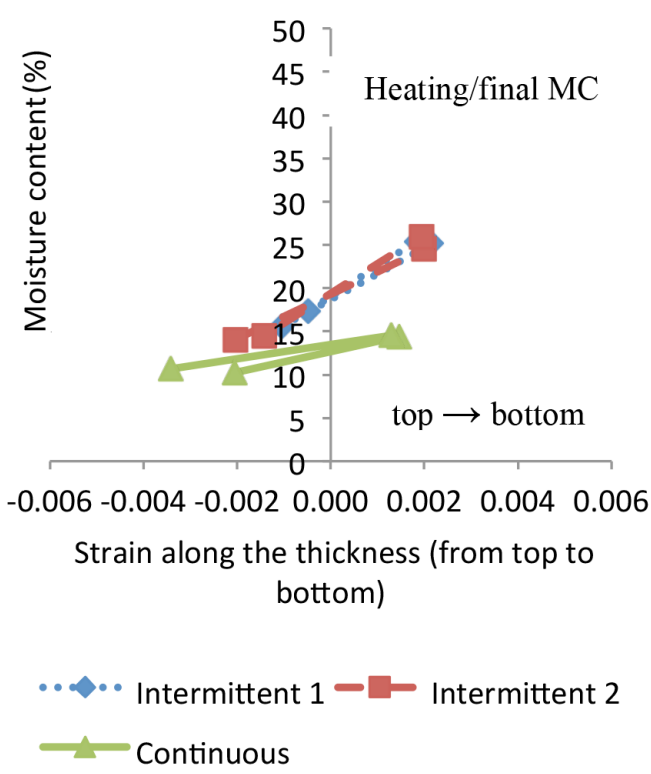

(c)

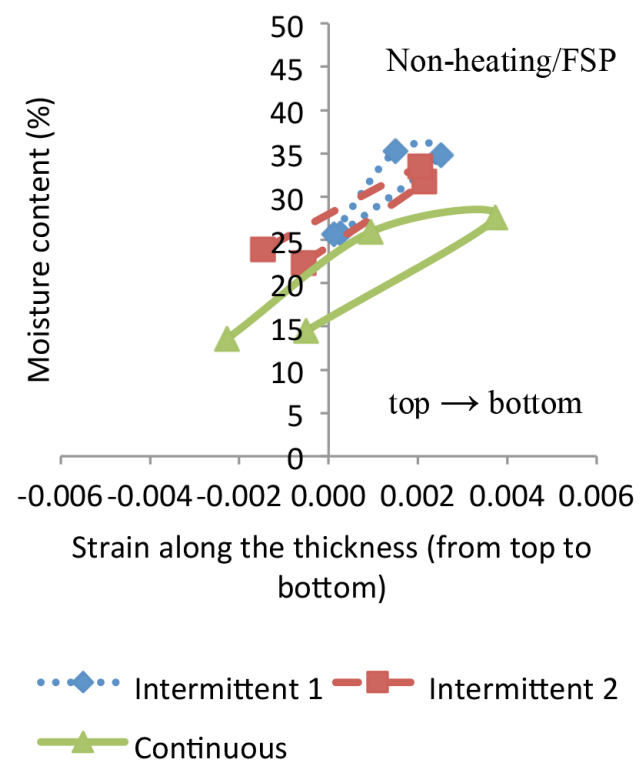

(b)

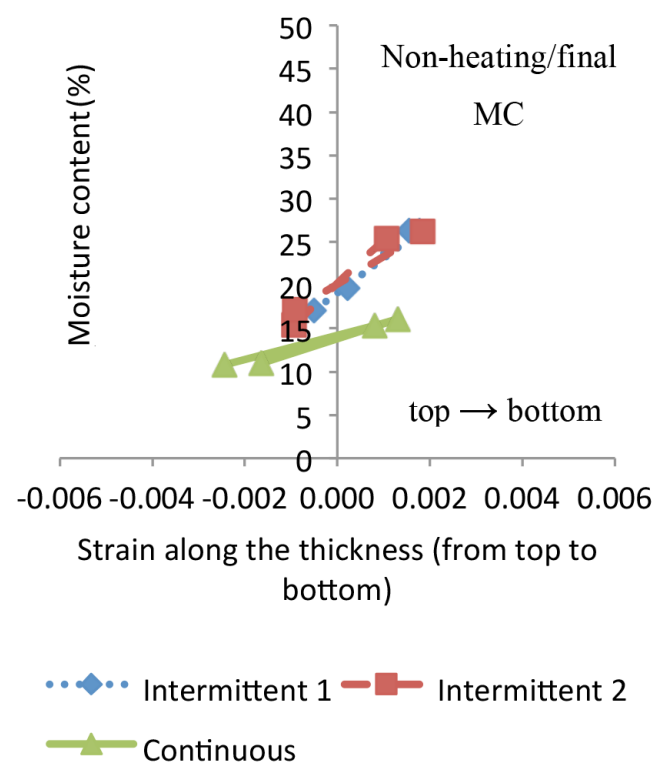

(d)

Figure 8 Viscoelastic strain along the thickness of the boards from Serisa Village, Papua New Guinea provenance exposed to different drying conditions; (a)-(b) fibre saturation point (FSP) level, (c)-(d) final moisture content (MC) level (10-15\%)

At fibre saturation point, only the continuously dried boards from PNG provenance developed mechano-sorptive strain along the thickness, which was $0.005-0.01$ greater than that from intermittent regime 2. At final moisture content, E. pellita boards from intermittent regime 1 developed mechano-sorptive strain that was $0.002-0.01$ smaller than values from the continuously dried boards. At this moisture level too, all continuously dried boards from Indonesia provenance developed larger mechano-sorptive strain, approximately $0.001-0.009$ greater than the boards from intermittent regime 2 . These findings indicated that selected intermittent regimes were not able to decrease the tendency of E. pellita boards to deform. 


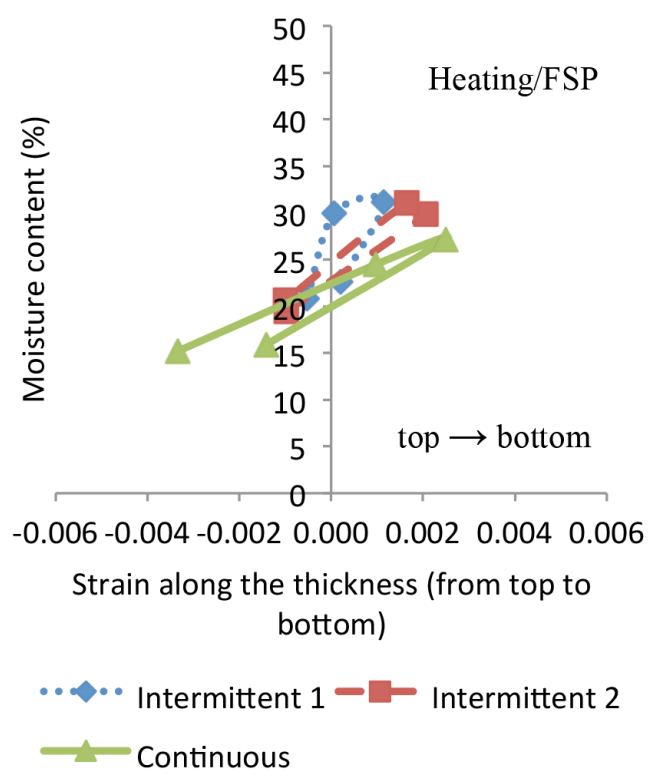

(a)

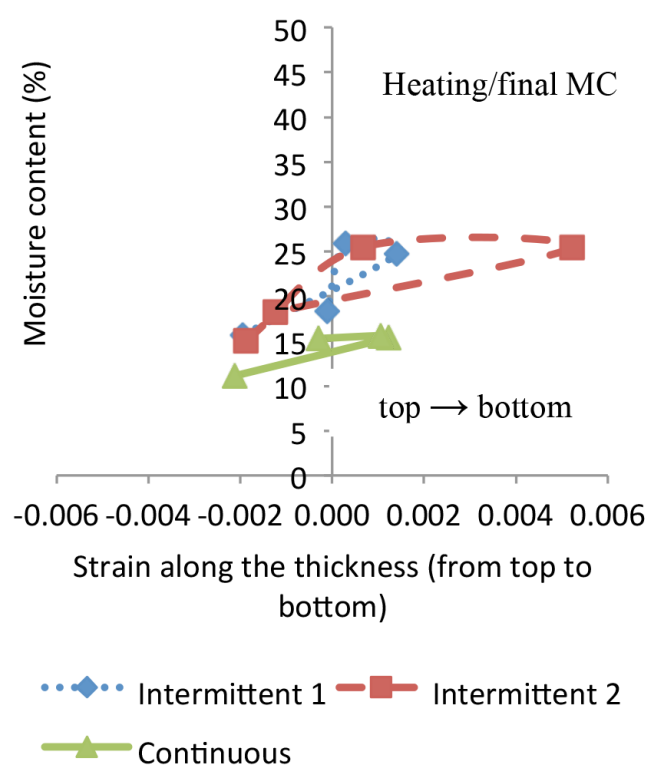

(c)

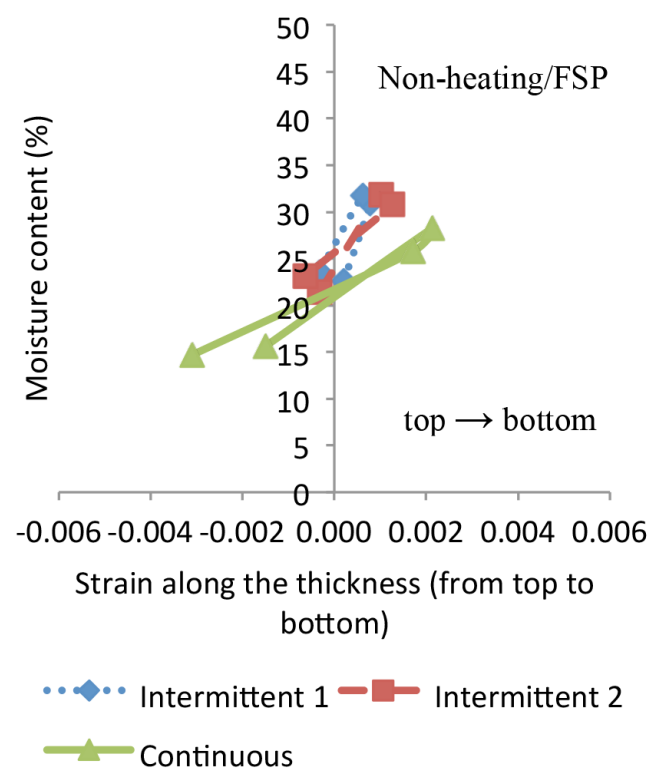

(b)

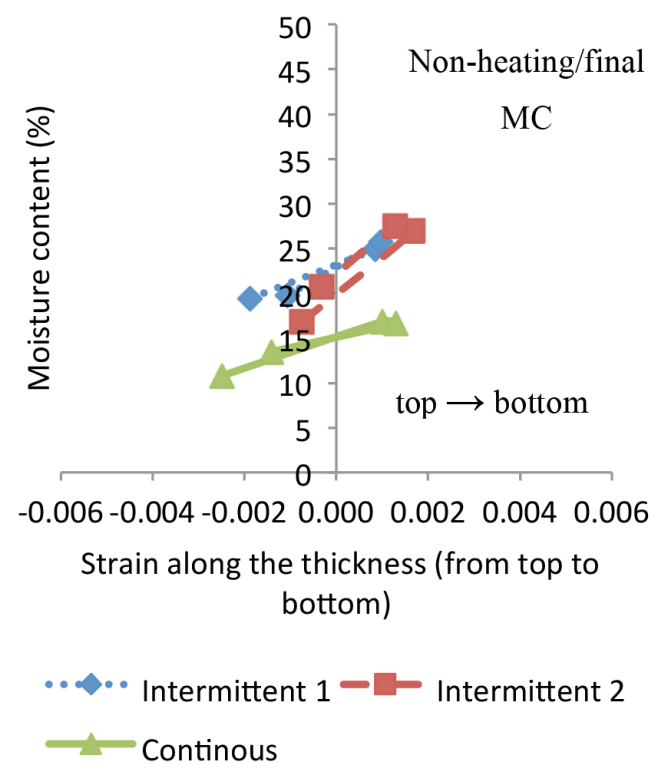

(d)

Figure 9 Viscoelastic strain along the thickness of the boards from Bupul Muting, Indonesia provenance exposed to different drying conditions; (a)-(b) fibre saturation point (FSP) level, (c)-(d) final moisture content (MC) level (10-15\%)

ANOVA confirmed that the drying technique, level of moisture content and interaction between drying technique and moisture level or provenance or both significantly affected the mechano-sorptive strain (Table 1). Tukey's test showed the mechano-sorptive strain in $E$. pellita boards from intermittent regime 2 was significantly different from those developed in boards from other drying regimes (Table
2). This result was possibly due to increased heating temperature in intermittent regime 2 when the samples reached fibre saturation point.

\section{CONCLUSIONS}

The study showed the drying technique applied, and not provenance factor, significantly affected 


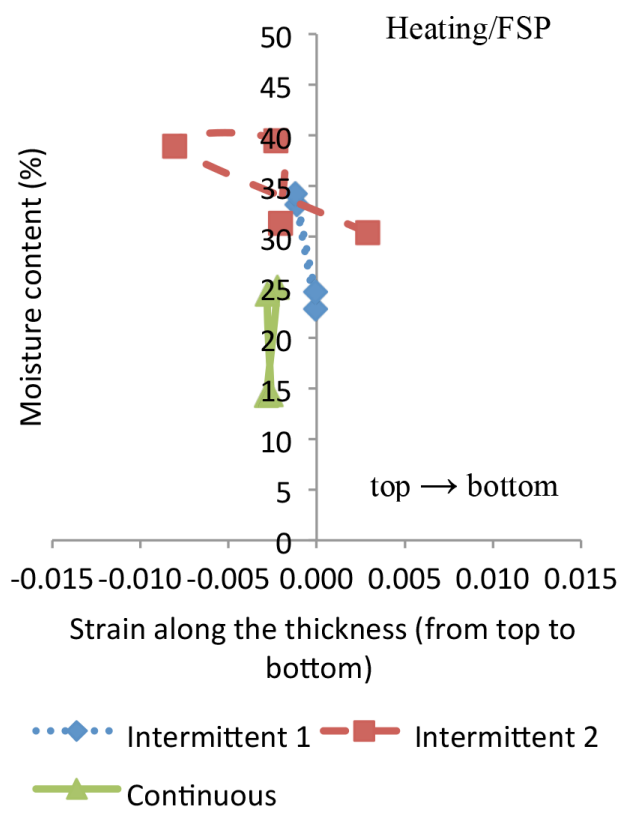

(a)

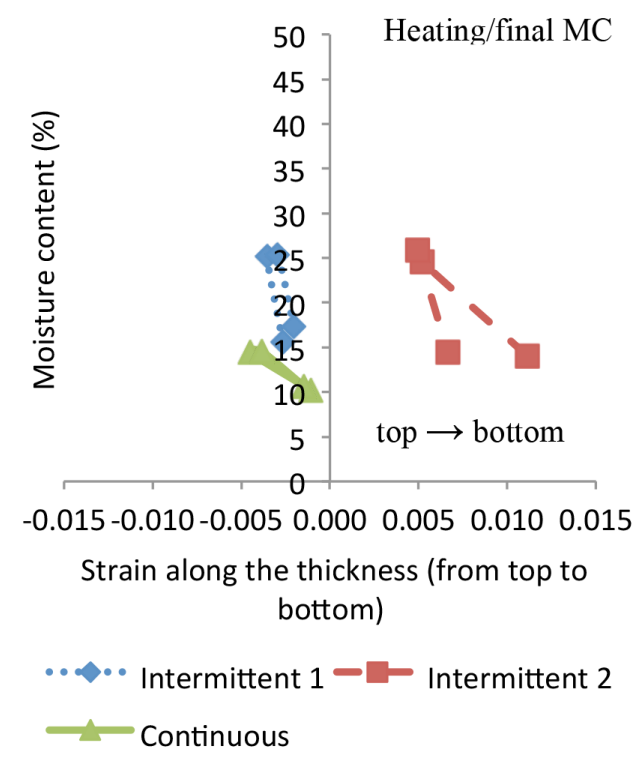

(c)

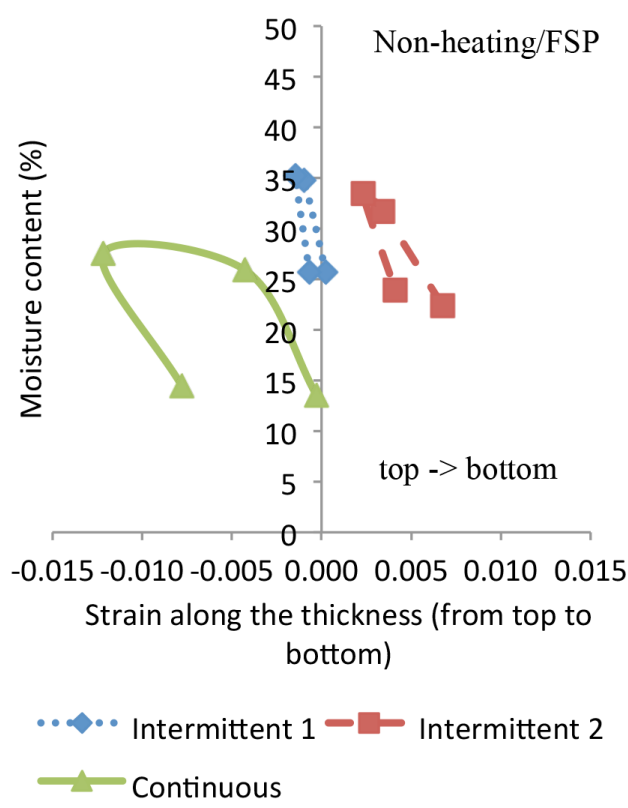

(b)

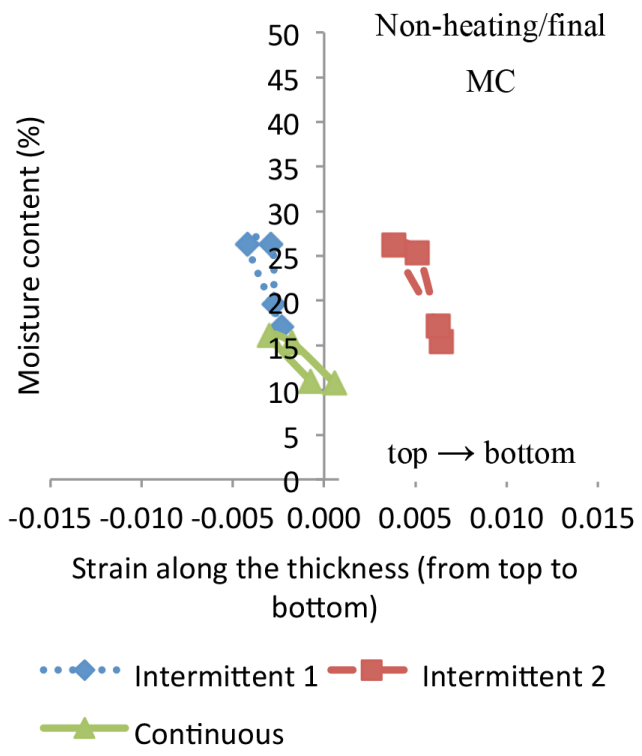

(d)

Figure 10 Mechano-sorptive strain along the thickness of the boards from Serisa Village, Papua New Guinea provenance exposed to different drying conditions; (a)-(b) fibre saturation point (FSP) level, (c)-(d) final moisture content (MC) level (10-15\%)

all strains developed in E. pellita boards. The use of intermittent regimes for drying $E$. pellita highlighted the importance of humidity to reduce the development of shrinkage and instantaneous strain. However, the potency of intermittent technique was not proven for either viscoelastic or mechano-sorptive strain. The shrinkage and instantaneous strains in
E. pellita boards from continuous drying were larger than those observed in the intermittently dried boards. Compressive stress was the major cause of shrinkage strain. Combination between compressive and tensile stresses was the factor causing the formation of instantaneous/elastic, viscoelastic and mechano-sorptive strains in the boards from all drying regimes. 


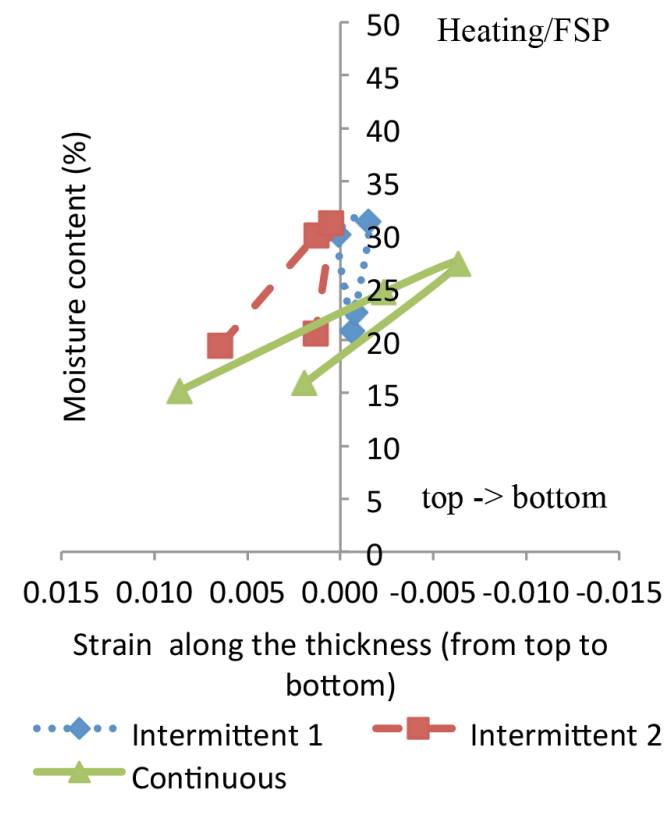

(a)

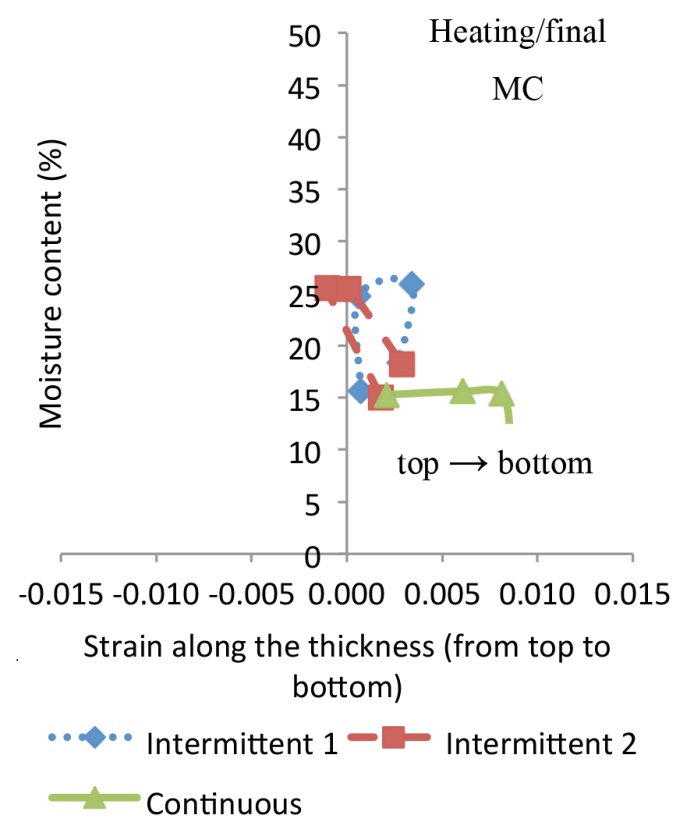

(c)

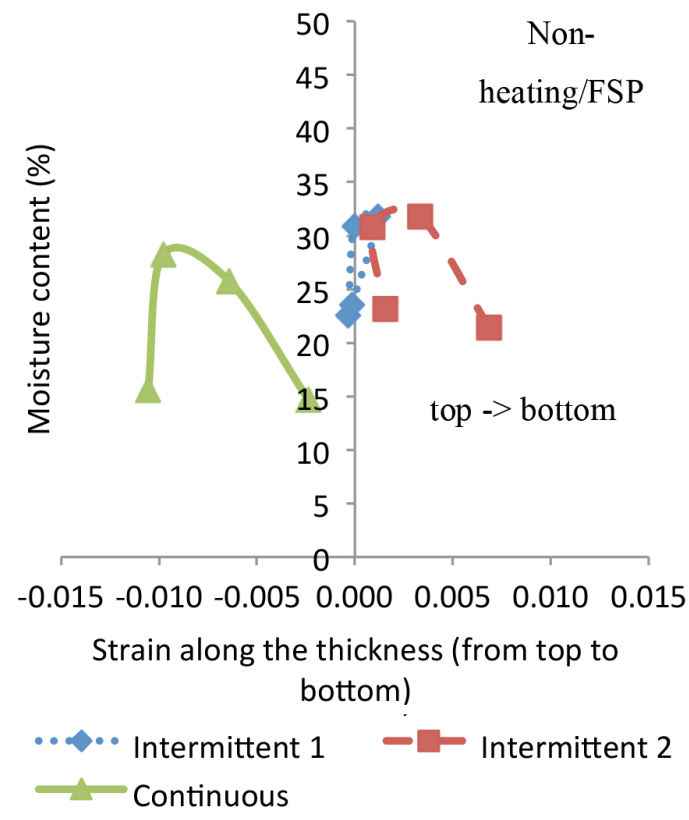

(b)

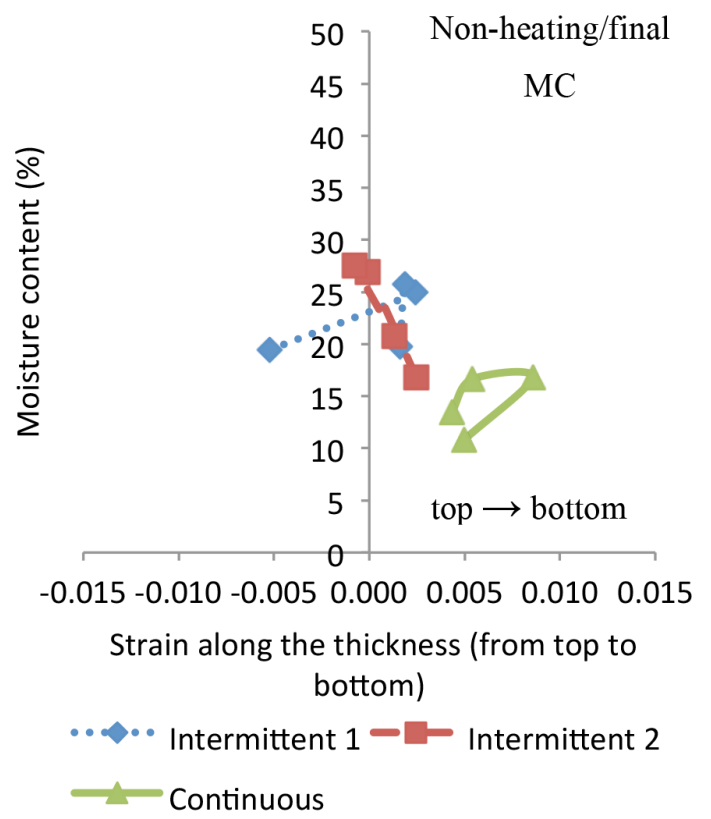

(d)

Figure 11 Mechano-sorptive strain along the thickness of the boards from Bupul Muting, Indonesia provenance exposed to different drying conditions; (a)-(b) fibre saturation point (FSP) level, (c)-(d) final moisture content (MC) level (10-15\%)

\section{ACKNOWLEDGEMENTS}

The author conveys her gratitude to ACIAR for providing the research funding through JAFReturnee Grant scheme, Nirsatmanto A and his team from CFBTI for fieldwork assistance, and Aftoni, Rahmat, Darta and Pardiono for laboratory assistance.

\section{REFERENCES}

Chadwick W \& Langrish T. 1996. A comparison of drying time and timber quality in the continuous and cyclic drying of Australian turpentine timber. Drying Technology 14: 895-906. doi: 10.1080/07373939608917130.

Chen T \& Gu L. 2006. Development of elastic strain and mechano-sorptive strain during conditioning of Eucalyptus camaldulensis lumber in batch kiln. 
Maderas. Ciencia y Tecnología 8: 49-56. http:/ /dx.doi. org/10.4067/S0718-221X2006000100006.

Fuller J. 2000. Determining the source of changing shrinkage rates during kiln drying. Drying Technology 18: 261-278. doi: 10.1080/07373930008917703.

HAQue MN. 2002. Modelling of solar kilns and the development of an optimised schedule for drying hardwood timber. PhD thesis, University of Sydney, Sydney.

Hir SY, Ha KS, NGUI ML ET AL. 2017. Assessment of plantationgrown Eucalyptus pellita in Borneo, Malaysia for solid wood utilisation. Australian Forestry 80: 26-33. doi: 10.1080/00049158.2016.1272526.

LANGRish TAG. 2013. Comparing continuous and cyclic drying schedules for processing hardwood timber: the importance of mechano-sorptive strain. Drying Technology 31: 1091-1098. doi: 10.1080/07373937.2013.769449.

LANGRISH TAG \& WALker JCF. 2006. Drying of timber. Pp 251295 in Primary Wood Processing: Principles and Practice. Springer, Dordrecht. https://doi.org/10.1007/14020-4393-7.

Latorraca JVF, Dias Af JR, Silva GC, Pace JHC \& Carvalho AM. 2015. Anelamento e vaporização de toras visando otimização do processo de secagem da madeira de eucalipto. Revista Brasileira de Ciências Agrárias (Agrária) 10: 273-279. http://dx.doi. org/10.5039/agraria. v10i2a4601.

Lazarescu C, Avramidis S \& Oliveira L. 2009. Modeling shrinkage response to tensile stresses in wood drying: I. Shrinkage-moisture interaction in stress-free specimens. Drying Technology 27: 1183-1191. doi: $10.1080 / 07373930903263111$.

Montes CS \& Weber JC. 2009. Genetic variation in wood density and correlations with tree growth in Prosopis africana from Burkina Faso and Niger. Annals of Forest Science 66: 713. https://doi.org/10.1051/ forest/2009060.

Sahri MH, AshaAri Z, Kaderi RA \& Mohmod AL. 1998. Physical and mechanical properties of Acacia mangium and Acacia auriculiformis from different provenances. Pertanika Journal Tropical Agriculture Science 21: 73-81. doi: http://psasir.upm.edu.my/ id/eprint/3681.

Sepulveda-Villarroel V, Perez-Peña N, Salinas-Lira C, SalvoSepulveda L, Elustondo D \& Ananias RA. 2016. The development of moisture and strain profiles during predrying of Eucalyptus nitens. Drying Technology 34: 428-436. doi: 10.1080/07373937.2015.1060490.

Wu Q \& Milota MR. 1994. Effect of creep and mechanosorptive effect on stress development during drying. Drying Technology 12: 2057-2085. doi: 10.1080/07373939408962219.

YUNIARTI K. 2015. Intermittent drying of Eucalyptus saligna. PhD thesis, University of Melbourne, Melbourne.

Zhan JF \& Avramidis S. 2011a. Mechano-sorptive creep of hemlock under conventional drying. I. The determination of free shrinkage strain. Drying Technology 29: 789-796. doi: 10.1080/07373937.2010.535939.

Zhan JF \& Avramidis S. 2011b. Mechano-sorptive creep of hemlock under conventional drying. II. Description of actual creep behaviour in drying lumber. Drying Technology 29: 1140-1149. doi: $10.1080 / 07373937.2011 .573154$.

Zongying F, Zhao J, Lv Y, Huan S \& Cai Y. 2016. Stress characteristics and stress reversal mechanism of white birch (Betula platyphylla) disks under different drying conditions. Maderas. Ciencia y Tecnología 18: 361-372. 